\title{
El proceso de cambio en psicoterapia
}

\author{
${\text { Lucía Blanco }{ }^{1} \text { y Ramón Riera }}^{2}$ \\ IARPP-España
}

Los autores utilizan un tratamiento psicoterapéutico de apenas dos años de duración para analizar cómo se desarrolla el proceso de cambio en psicoterapia. Siguiendo las conceptualizaciones del Grupo de Boston para el Estudio del Cambio Psíquico, se postula que para generar cambio en el paciente es más importante el cómo se está con el paciente (el cómo se interpreta) que el contenido cognitivo de la interpretación. La calidad relacional y en especial la actitud por parte del terapeuta de no esperar que el paciente confirme sus expectativas generará cambios en el sistema de memoria implícita del paciente. Lo cual, a su vez, generará cambios en la manera espontánea que tendrá el paciente de vivir el mundo (de reaccionar emocionalmente), que es el objetivo de toda terapia.

Palabras clave: Proceso de Cambio, Conexión emocional, Relación, Interpretación.

The authors use a psychotherapeutic process of just two years' length to analyze how the process of change develops in psychotherapy. Following the conceptualizations of the The Boston Change Process Study Group (BCPSG), it is postulated that in generating change in the patient, how one is with a patient (how interpretations are made) is more important than the cognitive content of interpretation. The quality of the relationship and especially the therapist's stance of not expecting the patient to confirm her expectations will generate changes in the patient's implicit memory system. This, in turn, will generate changes in the spontaneous way in which the patient will have to experience the world (ie. react emotionally); this being the goal of any therapy

Key Words: Change Process, Emotional Connection, Relationship, Interpretation.

\section{English Title: Change Process in Psychotherapy}

\section{Cita bibliográfica / Reference citation:}

Blanco, L. y Riera, R. (2016). El proceso de cambio en Psicoterapia. Clínica e Investigación Relacional, 10 (3): 793-814. [ISSN 1988-2939] [Recuperado de www.ceir.info ]

DOI: $10.21110 / 19882939.2016 .100314$

\footnotetext{
1 Psicóloga psicoterapeuta relacional, presencial y online. Directora del Centro Sanitario: "Consulta de Ayuda Psicológica Lucía Blanco", situado en Madrid c/Numancia, 6. Piso $3^{\circ}-7$. Tfno.: 670761487. Email: blancorejas@gmail.com. Titulada EUROPSY - EFPA (Federación Europea de Asociaciones de Psicólogos). ESPECIALISTA UNIVERSITARIA EN CLÍNICA Y PSICOTERAPIA PSICOANALÍTICA. Universidad Pontificia Comillas de Madrid en colaboración con la Escuela de Libre Enseñanza del Psicoanálisis (ELIPSIS). Perteneciente al Colegio Oficial de Psicólogos de Madrid desde 1.981. A la Sociedad FORUM de Psicoterapia Psicoanalítica. A IARPP internacional. Soy Vocal de la Junta Directiva de IARPP- España. Otras asociaciones: FAPYMPE, AIEDEM, etc.

${ }^{2}$ Médico-Psiquiatra y Psicoanalista. Presidente de Honor de IARPP-España y Miembro de Honor del Instituto de Psicoterapia Relacional. Autor de La Conexión Emocional (Barcelona: Octaedro, 2009)
} 
En este artículo nos vamos a centrar en qué factores son determinantes para que se dé el proceso de cambio en psicoterapia. Ha sido muy interesante para nosotros ir observando cómo alguien, a quien Ilamaremos Vicente, que llegó a la consulta muy paralizado por sus angustias y que no podía hacer nada que no fuera estar sufriendo, pudo iniciar un cambio espectacular en un corto espacio de tiempo, apenas dos años, en el cual su progreso fue notable y manifiesto. Esto es lo que nos animó a investigar qué experiencias habían sido cruciales en este proceso de cambio. A continuación describiremos en detalle cómo ha sido nuestro trabajo con este paciente, y expondremos nuestro punto de vista acerca de cómo se da el cambio en psicoterapia, resaltando cómo el apego seguro del paciente con la terapeuta ha sido clave para replantear la acomodación patológica (Brandchaft 2007), en la que Vicente estaba sumergido y de la que comentaremos más delante.

\section{LOS INICIOS DEL PROCESO TERAPEÚTICO}

Unos conocidos lejanos de la terapeuta (Lucía Blanco) cuentan el drama en el que está viviendo su hijo de 30 años. Devorado por la angustia, está muy desestabilizado, y aunque necesita ayuda psicológica no quiere hablar ni ver a nadie, no tiene ánimo para hacer nada. Cuand o finalmente Vicente llega a la consulta enseguida se observa que se trata de un chico tan aterrorizado, desbordado y desorganizado por el mundo caótico de angustia en el que vive, que le resulta imposible poder pensar en lo que le está pasando. Como todo paciente con un pasado traumático, tiene una convicción emocional nunca pensada en palabras, por tanto grabada en su memoria emocional (memoria implícita o procedimental), que si tuviéramos que expresarla en palabras sería: "nunca te permitas volver a visitar los fondos de los pozos en los que has estado". Vicente tenía terror a poder volver a revivir los pozos en los que había caído en su pasado, por su convencimiento de que cuando se entre en uno de estos pozos ya no se podrá salir del mismo. Durante el tratamiento, la terapeuta le mostrará a través de su lenguaje paraverbal (tono y ritmo de voz, silencios, lenguaje corporal y expresión facial) que no está tan asustada como él, que siente lo que él siente pero no de una forma tan desbordada y tan caótica, que no piensa que lo que le ocurre a él le va a durar para siempre sino que es algo transitorio, y que tiene la confianza de que podrán descender juntos a los pozos traumáticos de Vicente sin quedar atrapados en ellos. La terapeuta le irá transmitiendo su interés genuino y auténtico de conocerlo, de saber de su sufrimiento, y de entender qué momentos de su vida le pueden haber marcado. Esa actitud emocional de la terapeuta es contraria a la de Vicente que es la de ir disociando y apartando. Él, a través de sus neuronas espejo y de los circuitos neuronales compartidos con su terapeuta (Pally 2010), va a empezar a experimentar sus angustias de una manera 
algo parecida a cómo la terapeuta las vive, es decir de una forma más soportable. La soportabilidad es un concepto clave en psicoterapia: el objetivo de toda terapia es que las vivencias insoportables para el paciente, que no tienen otro procesamiento posible que el de la disociación, puedan ser vividas con la compañía del terapeuta. Sólo podemos pensar en aquellas vivencias que nos resultan soportables.

QUIÉN ES VICENTE CUANDO LLEGA A LA CONSULTA

\section{Construyendo una narrativa de los episodios traumáticos que habían quedado disociados.}

En esta parte construiremos una narrativa de los hechos significativos en los que Vicente no había podido fijar su atención. Gracias a la compañía de la terapeuta, Vicente puede empezar a visitar territorios de su memoria que nunca había podido explorar. La terapia ha servido para poner la lupa en aquellas situaciones que habían quedado disociadas.

Desde un inicio, se pone el énfasis en que Vicente no debe imponerse con su fuerza de voluntad a sentir de manera opuesta a como siente. Poco a poco él irá asumiendo que para transformar su manera de sentir deberá primero detectar y entender el sentido de sus respuestas emocionales automáticas.

A continuación describiremos los distintos episodios de la vida de Vicente que nunca antes de la terapia habían sido recordados de manera explícita.

\section{Ingreso en el hospital por deshidratación.}

Vicente cuenta que a los 2 años se deshidrató y le tuvieron que llevar al hospital y "fue muy trágico porque, según me cuentan, estaba muy malito". Y es que a la madre no la dejaban pasar más que a las horas de visita según era la costumbre de entonces. Y como si estaba solo se negaba a comer, tuvieron que dejar que su madre fuera a las horas de las comidas, pero luego se tenía que ir. La separación de su madre le generaba a él mucha irritación y gran malestar, él lo expresa asi: "mi madre dice que yo gritaba y me quitaba la vía y 
finalmente me tuvieron que atar. Y que a partir de ahí yo no me_podía soltar de su mano y ahora nunca puedo estar solo". Estuvo mes y medio en el hospital. Después la madre habló con un médico conocido y éste le dijo que le sacaran del hospital y le llevaran a casa y que él haría el seguimiento médico, porque si no allí se iba a morir. "Ahora odio todo lo que huela a hospital, a médicos, a farmacia", dice. Al ser preguntado cómo cree que se sentiría un bebé que le ocurre una cosa tan horrible, sin ningún tipo de emoción responde: "Creo que a lo mejor tendría un poquito de angustia, no lo recuerdo, pero dicen que después me costó mucho volver a retomar lo que yo había sido y me hice muy introvertido".

Él había negado siempre la importancia de este episodio, no lo recordaba, no creía que eso fuera significativo en su vida. Fue muy dificultoso conseguir que Vicente centrara su atención en este episodio e intentara pensar en cómo le había afectado, porque durante sus 30 años de vida se había estado esforzando en todo lo contrario: quitarle importancia, no pensar en ello, no creer que fuera un hecho relevante. Por eso, cada vez que la terapeuta intentaba hablar de este tema, lo que Vicente hacía era evitarlo y pasar a uno nuevo. Ahora después de año y medio de trabajo dice: "yo sé que me influyó mucho, ¡claro que me influyó! porque me mimaron excesivamente, me criaron entre algodones y siempre fui muy dependiente". Curiosamente, en un primer momento Vicente construye la narrativa de que fueron los mimos y los cuidados lo que le dañó, y de esta manera lo insufrible, lo insoportable, podía quedar disociado fuera de los horizontes de su experiencia (Stolorow et al, 2002 ). Por supuesto que lo traumático de esta situación fueron las insoportables y caóticas vivencias de abandono que vivió en el ambiente de un hospital hostil. Es muy típico en los estados traumáticos que el paciente disocie los abandonos y los malos tratos que ha sufrido y que intente colocar el origen de sus problemas en defectos propios. En este caso Vicente lo fija en ser un niño malcriado, mimado y dependiente. Por ello, uno de los objetivos de la terapia fue transformar la narrativa "he sido un niño demasiado cuidado" por "he sido un niño que ha estado muy solo".

\section{La hiperhidrosis.}

Vicente de pequeño presentó el síntoma de hiperhidrosis. (La hiperhidrosis es una secreción excesiva de sudor. Normalmente la sudoración mantiene la temperatura corporal eliminando el calor sobrante del cuerpo. En el caso de Vicente al existir un inapropiado funcionamiento del sistema simpático, se produce una sudoración desmesurada en 
determinadas zonas del cuerpo. La hiperhidrosis produce tanto malestar que llega a condicionar la vida de quien lo padece)

Tampoco Vicente había querido hablar con nadie del problema de su hiperhidrosis. A tal punto llegó que nunca había tenido novia para no tener que explicarle su problema del sudor. Esto nos da una idea de cómo es de nueva su relación con la terapeuta. "Fuimos a muchos médicos y nadie sabía lo que tenía, nadie me decía nada. Me sentía muy mal, frustrado porque nadie me entendía. Eso me hizo pensar que no tenía solución. Y ese fue el trauma. Yo no quería que lo supiera nadie, solo mi madre". Por lo cual en la terapia le molestaba mucho revivir con su terapeuta las dolorosas sensaciones de incertidumbre acerca de lo que le había pasado.

La sensación de repugnancia que con su sudor provocaba en los demás era otra vivencia que rayaba en lo insoportable. Era algo muy desagradable para él y procuraba evitarlo, con lo cual, la terapeuta siempre que se interesaba por este tema tenía que medir mucho sus palabras y ser muy cuidadosa y respetuosa. Veamos un ejemplo de este modo no invasivo por parte de la terapeuta de abordar esta temática:

Lucía: "disculpa, no sé si te incomoda que te pregunte por el sudor, lo hago porque yo quiero sentir de la mejor manera posible lo que tu sientes, pero si tú ves que te incomoda no hablamos de ello. Yo sé que es un tema muy delicado para ti y que no quieres hablarlo nunca con nadie".

Vicente: "No, no me importa contártelo a ti".

Y lo describió de la manera siguiente:

"A los 6-7 años tuve muchos problemas, cuando empecé a ir al colegio me hacía pis de los nervios, tenía las manos rojas, moraditas, llenas de agua, mojaba mucho el papel, los niños me decían que les daba asco, no querían ir conmigo y no paraban de decirme por qué sudaba tanto. Sentí el rechazo, nadie se quería sentar conmigo, ni jugar conmigo, y todo esto me avergonzaba mucho. Fue mucho dolor porque era como si me dijeran que no me querían y que no me iban a querer nunca. Eso me ocasionó que me fuera aislando y me influyó en la relación con mis compañeros. En mi casa tenía problemas, nadie me comprendía. Yo recuerdo que les preguntaba a mis padres porqué me pasaba eso y mi padre me decía que no me preocupara que ya se me pasaría". 
A lo largo de este relato aparece en él un llanto emocionado sin apenas lágrimas, que seca rápido como para que no se note su emoción al contarlo. Y prosigue:

"Soy un enfermo, tengo una enfermedad vergonzante, esto no se cura. No puedo utilizar ciertas cosas, como por ejemplo no puedo usar prendas que tengan lycra, no puedo dar la mano a nadie, no puedo tocar el piano que me gustaba tanto, no puedo elegir ciertas profesiones, y esto me ha generado mucha angustia, me siento un bicho raro. Me refugié en los estudios, saqué siempre muy buenas notas y me aficioné mucho a leer. A los 19 años me operaron de hiperhidrosis. Me hicieron una simpatectomía torácica. El posoperatorio fue bastante malo y doloroso. Cuando salí del hospital, aunque tenía muchos dolores, me fui con los amigos a la discoteca para que no se enteraran de lo que me había pasado. Después de la operación lo pasé mal, pero me compensaba porque las manos ya no me sudaban tanto. Físicamente estaba mejor pero poco tiempo después comprobé que no me había cambiado tanto la vida, me habían desaparecido los sudores en las manos, pero seguía sudando en exceso en el resto de mi cuerpo, me escurría por el sudor en los pies y me caía al suelo, pasaba de tener un calor exagerado a estar frío, muy mal, aunque es verdad que era más llevadero". De repente dice a la terapeuta: "¿Sabes? Ahora que lo estoy hablando contigo me parece muy interesante lo que estamos descubriendo".

Este fue un hito importante. Decir él de repente que no estaba tan mal contarlo, que le estaba sentando bien, que se estaba desahogando, significó que empezaba a conectar, que aquella experiencia no era tan insoportable como para no poder ser hablada, que empezaba a salir de la disociación. Para nosotros fue algo muy relevante. Porque uno de los trabajos que hacíamos era que pudiera replantearse que lo que le resultaba totalmente insoportable, al poderlo compartir con la terapeuta, se podía convertir en llevadero. Entonces podía tener la experiencia sorprendente de que lo que había vivido siempre como amenazas de recaer en el pozo, ahora lo notaba como algo que le reconfortaba. Y le resultó interesante comprobar que con la comprensión del otro, en contra de lo que había anticipado, no caía en el pozo y en la catástrofe. Eso le aportaba la sensación de dominar lo que le estaba pasando, que lo que le ocurría no le dominaba a él sino que era él quien podía reflexionarlo, ordenarlo, encontrarle un sentido, una coherencia; era notar que el otro también lo podía sentir, que el otro no se asustaba, con lo cual él tampoco se asustaría tanto. Este tipo de dinámica explicado en esta viñeta es lo que nos resultó relevante y muy esperanzador porque significaba el inicio del cambio psíquico. La terapeuta siente que la 
verbalización de estos recuerdos fue un importante punto de inflexión en el proceso terapéutico.

Pero supimos que había que ir muy despacio y con mucho cuidado, y al mismo tiempo con mucho interés en sentir lo que él sentía y en acompañarle en su dolor, para ayudarle a que sus experiencias emocionales, hasta el momento tan insufribles, pudieran empezar a ser vividas de manera progresivamente más nítidas y formuladas, es decir menos disociadas (Stern 2003). Veamos un ejemplo:

ucía. Ya entiendo que te sentirías muy frustrado.

'icente: ¡Sí, y qué impotencia!, pero decidí que tenía que salir adelante, no quería que me enciera la enfermedad.

.ucía: Dime si te sientes mal en cualquier momento, vamos a hablar sinceramente, y yo ambién voy a hacerlo así, aquí no se critica a nadie, estamos tu y yo, en equipo, y no va a salir le aquí lo que pensemos o digamos.

'icente: No, no me siento mal contigo, si me hubiera sentido mal ya me habría ido, de forma ducada te hubiera dicho que me tenía que ir. Estoy bien, me siento bien.

.ucía. Veo que hay una gran fuerza en ti para sostener eso que dices. Pero estoy pensando qué pasó con todas esas emociones que hemos ido viendo?

'icente: No sé, se me pasaron. Yo llegué a controlar, supe cómo manejarlo. Después de la ıperación, ese año al principio no me ubicaba bien en ningún sitio. Estaba en la facultad, en rimero de filología, y tuve que tomarme un año sabático, ya que no dormía, perdía peso y al inal tuve que acudir al psiquiatra. Me mandó unas pastillas y me sentí estupendo y una vez lice la prueba de tomar más y pensé que así me sentiría mejor. Y cuando me desperté estaba n el hospital. Te aseguro que yo no me quise suicidar, me gustó como me sentía y me dejé evar. Con el psiquiatra no me fue mal, pero me mandó a la psicóloga porque decía que tenía jue sacar lo que tenía dentro. Con ésta me fue fatal, noté su mirada sobre mis manos y fue atal, no me gustó su reacción, no me sentí bien, me sentí rechazado, como un bicho raro. Así jue me fui y no volví.

Esta explicación de los problemas que había tenido con la psicóloga anterior fue muy útil desde el principio de la terapia para entender que Vicente necesitaba un tipo de aproximación muy respetuosa, muy cuidadosa, donde hubiera lugar para poder hablar de 
la vergüenza que le daba todo este tema del sudor de las manos. Y fijándonos en la viñeta de la intoxicación con las pastillas se nos muestra claro el enorme caos en el que vivía Vicente en aquel momento. $Y$ es este mismo caos el que le lleva a perder el control de la ingesta y usar una sobredosis. Es un indicador de su desesperación y con ello nos muestra la avidez por la medicación, la virulencia del sufrimiento de este chico y la urgencia intensísima de encontrar alivio. Este hecho supuso un gran lio para los padres porque en urgencias creyeron que había sido un intento de suicidio y tuvo gran dificultad para explicar que lo había hecho sin ninguna intención.

\section{3.- El accidente de la madre}

Cuando estaba preparando las oposiciones para ingresar en la Unión Europea, hubo un problema familiar que fue especialmente duro para Vicente. La madre comete una grave imprudencia cuando va conduciendo. Para acortar, se metió en un tramo de carretera en dirección contraria ocasionando un accidente mortal. En la actualidad este caso está pendiente del resultado del juicio y posible condena. Además en esos momentos murió su tía, que para él era como una madre. Vicente lo narra así:

"Se me hundió la vida. Mi madre había sido mi gran apoyo, pero en esos momentos era para mí el demonio por lo que había hecho. Sentí una gran decepción. Por muchas razones que hubiese en esta vida lo que había hecho no lo puede hacer nadie y nos ha salpicado a todos. No acepto que pase esto, el peaje que se paga es estar mal, supone no vivir, quiero que se termine esta odisea, quiero olvidarme de ello y al mismo tiempo no lo puedo dejar de pensar. Este hecho de mi madre me trastornó, me hizo y me sigue haciendo perder el equilibrio de tal manera que a veces no sé ni dónde estoy, no me quiero rendir, pero no sé cómo canalizarlo, siento miedo a tener malas noticias cuando llegue la sentencia definitiva. Es esta espera de la sentencia lo que me hace tener una enorme inseguridad, le doy muchas vueltas, se me olvidan las cosas, no puedo dejar de pensar en ello. Además es de suponer que mi honor quedará por el suelo, porque si mi madre sale manchada, yo también saldré manchado. Y eso me angustia mucho porque a partir de ahora no voy a ser nadie, yo seré el hijo de esta madre manchada. Todo esto de mi madre fue una complicación tan grande para mí, que lo que hacía entonces, que era preparar unas oposiciones, tuve que dejarlo. Me volví loco con lo que nos podía pasar, no era capaz de concentrarme, no era capaz de nada, sentíque el tsunami me había arrasado. No me pesó dejarlo, pero sí me dolió y me sigue doliendo y a veces me resulta insoportable, que tuve que dejar todo y renunciar a un futuro brillante cuando estaba llegando a la meta de mi carrera. Yo pensaba: una enfermedad te viene dada por la vida, pero eso no lo da la vida. 
Es lo peor que me ha podido pasar. Sentía mucha presión, necesitaba hablarlo porque me comía, pero mi padre dijo: de eso no se habla más en esta casa. Ahora me hace daño contártelo, sé que saldré de aquí peor, pero necesito sacarlo, necesito desahogarme, contarlo a alguien que me comprenda y no me juzgue. Quiero que termine esto, que llegue la sentencia y me saque de la incertidumbre, y a la vez siento que tengo miedo al desenlace".

Pensamos que estaba bien que se desahogara, que se quitara la coraza y explicara descarnadamente todo su sufrimiento, su horror. Esto era una señal muy buena. Significaba que había alguien confiable para él donde poder depositar todo esto. Al mismo tiempo necesitábamos tener en cuenta la ansiedad y la vergüenza que pudiera tener al comunicar sus problemas, sin sentirse por eso desvalorizado.

En una ocasión de mucha tensión la terapeuta le dice: "Yo entiendo que para ti el problema de tu madre ha sido un auténtico terremoto, un tsunami (Bromberg 2009, 2011), como si un mar te arrastrara, como en la película de Lo imposible" (por ese tiempo era actual esta película).

"Sí, dice él, yo pienso que siempre voy a estar marcado, que siempre tendré una sensación de pánico, de mucho malestar, como de nausea". Al contar esto está muy tenso.

.ucía: parece que vives para sufrir, pero ¿te apetecería dejar de sufrir?

'icente: "Si claro que quiero, porque ahora no se lo que quiero, te diría que nada, me agobio on todo, me supera la vida, estoy harto, mis amigos han podido formar una familia y yo no, iero no podía dejar solos a mis padres y a mi hermano. Mi madre lleva un año distinta, liferente, era muy activa, pero tiene otra cara, la expresión de ahora es más triste. Ella intenta parentar, pero yo lo noto y a mí me afecta emocionalmente, siento tristeza, temo que todo aya a cambiar. Siento nostalgia porque con mi madre tenía muy buena relación y la sigo eniendo, pero las cosas han cambiado porque ahora me entero de cosas que antes pasaba ır alto: ya no puedo compartir con ella. Y pienso ¿ahora con quién lo voy a compartir? mejor jue con ella con nadie. Siento miedo, mi madre es mayor y yo no puedo darle disgustos.

Siempre quiso mantener una imagen de tener una madre sana y ahora empieza a hacer el duelo de esta imagen cuando dice: "qué mal está, qué poca cosa es, que reacciones tiene". Cuando estaba en su disociación y mientras peleaba con ella sentía que luchaba con una madre fuerte pero se empieza a dar cuenta de cómo han sido en realidad las cosas para él, 
empieza a percibir toda la relación con su madre y ve que es una fuente de su angustia. E cambio está en enterarse de lo que pasa y lo que le ha pasado.

Pero ¿por qué vive esto que ha hecho su madre como una mancha que a él le impedirá crecer? En parte porque para él el centro de su vida que es su madre, se puede desmoronar y si se rompe y pasa a ser juzgada, todo lo que Vicente ha estado luchando en su vida para sostenerla lo pierde definitivamente, Por ello ya no puede estudiar, ya su futuro es catastrófico. Es aquí donde podemos comprobar el rol reversal del que hablaremos al final del siguiente apartado.

\section{4.- El hermano}

Su hermano es bastante mayor que él y es otro de los aspectos traumáticos de su vida. Cuenta y cuenta de su hermano sin parar desde el comienzo de la psicoterapia. Es de suponer que para su hermano la llegada de Vicente debió ser una contrariedad, el hermanito enfermo que quita protagonismo. La relación entre ellos es complicada porque el mayor le domina pensando que tiene que cuidarle y Vicente se queja de que su hermano siempre ha tenido necesidad de protagonismo, que es impulsivo, no piensa nada de lo que hace. Lo cuenta Vicente de esta manera:

"A mí me invade, me cuida tanto que me hace sentirme como un inválido, diminuto y eso me duele y si no hago lo que él quiere se enfada mucho conmigo y a mí me da mucha rabia porque siempre tengo que claudicar. Cuando discutimos me vuelve loco, pierdo el equilibrio y luego veo que él está como si no hubiera pasado nada y además mejor que yo. Pero no le puedo decir nada, prefiero el silencio y hacer como dice mi padre: que los hermanos se tienen que querer mucho. Él me cuenta sus problemas, aunque yo tengo los míos, pero de eso no se ocupa. No es fácil razonar con él porque tiene su discurso, lo suelta y se queda bien, pero no soluciona el problema y yo me quedo muy mal. Además cuando me toca hablar a mi desconecta y se acabó el diálogo. Mi hermano saca lo peor de mí. La relación de él con mi padre es curiosa, cuando discuten mi padre se enfada y no dice nada, y es verdad que mi padre no se tambalea como yo, pero aunque de momento parece que a él no le afecta tanto porque no se pone a discutir como yo, luego está 2-3 días que no habla con ninguno de nosotros. Cuando mi hermano se pone así, yo tengo que dejar todo y pararle. ¡Qué carga! Necesito desahogarme contigo porque no lo puedo hacer con nadie más". 
Entendemos que cuando Vicente utiliza la expresión "desahogarse" se refiere a que al compartir sus vivencias hasta el momento insoportables, siente que puede regular de una manera más eficiente su estado de ánimo. Y cuando se calma puede escuchar y volver a repensar ideas que se han ido quedando en su cabeza de otras sesiones.

Vicente y su terapeuta han ido trabajando que él pudiera sentir en su piel que es comprendido, que es verdad que su hermano le altera mucho y por eso necesita saber cómo se puede proteger de él proponiéndole que como su hermano no va a cambiar, tendrá que cambiar él, y que buscaremos estrategias que le ayuden sobre todo en el grado de cómo le impacta. Si su hermano le intoxica y no puede evitarlo, a lo mejor es interesante que de momento pueda alejarse de él cuando se enfada, marcharse, poder hacer otra cosa. Por ejemplo venir a la terapia y contarlo para no contagiarse, y que al hablarlo pueda ver claro qué es lo que le pasa, qué siente cuando ocurre eso y no tenga que disociarlo, como si no hubiera existido, como le pasaba antes. Porque ahora es diferente para él, ahora no está solo como antes, ahora está con su terapeuta, los dos trabajando juntos y lo que le pasaba antes ya no va a ocurrir más, porque ahora tiene en la terapia un espacio para él solo. Veamos cómo él lo cuenta:

'icente: Sí, necesito oxígeno, respirar, paz. Mi hermano me pone muy nervioso, me crea nucha angustia. Cuando me llama por teléfono, cosa que es muy frecuente, lo primero que ienso es: ya la ha liado con alguien y a ver qué le digo yo ahora, cómo lo soluciono, qué puedo lacer yo.

.ucía: Parece que te sientes con tu familia colgada en los hombros.

'icente: Si, así es, ahora me voy dando cuenta. Aunque soy el enfermo y parece que todos ne cuidan a mí, es al revés, soy yo el que tengo que cuidarles a ellos. Yo no puedo ir a ningún itio más lejos de una hora, porque no estoy a gusto por si ocurre algo a mis padres o que mi ıermano la lie. Si voy a algún sitio pienso: ojalá me dejen estar tranquilo. Me he costumbrado a eso, dice mi madre que no me lo tome así. Pero me tienen en vilo con las amadas.

En estos hermanos podemos observar los dos tipos de role reversal de los que nos habla Lyons Ruth (2011), (Riera 2011). Si utilizamos la metáfora de un barco donde el capitán es 
alcohólico, cuando la tripulación ve que el capitán no puede hacerse cargo, ellos toman el control del barco. Si lo superponemos al contexto de la familia como debió ocurrir con sus padres, los dos hermanos toman el control de la situación, pero utilizando un rol reversal cada uno de forma contraria: Uno toma el rol de cuidador, que es lo que hizo Vicente. El otro tomar el rol de controlador, que es lo que hizo el hermano. Esto último es típico de los niños tiranos, los cuales exigen de forma desmedida y los padres acaban cediendo a todos sus impulsos y sus deseos. Este papel es el que juega el hermano con el mensaje implícito de: "si no hacéis lo que yo digo monto un lio", y los padres no organizan, no imponen un criterio ordenado en momentos de especial dificultad, y se quedan paralizados. En esta familia este hermano tomó el papel de ser el sano y el espabilado y aplastó a Vicente y le obligó a hacer el papel del enfermizo al que hay que cuidar. Aunque como hemos visto, en realidad es Vicente el que de forma no evidente cuida de su hermano.

Esta función de los dos hermanos que para nosotros fue algo muy evidente, no lo era para él. Que Vicente haya logrado entender esto ha sido un proceso lento, fruto de muchas horas de dialogo terapéutico. Este trabajo ha ido permitiendo que Vicente desplegara una actitud de autoprotección ante su hermano que previamente no tenía.

\section{El papel relevante del abuelo.}

El abuelo materno vivía con la familia y Vicente siempre que habla de él se emociona. Era callado. Murió cuando él tenía 16 años. Le echó mucho de menos y lo pasó muy mal. Cuando Vicente llegaba a casa del colegio siempre estaba él porque los padres estaban trabajando. Era una persona que le comprendía. Él lo narra así:

'icente: No lo he encontrado en nadie después, convivíamos en complicidad. Yo me parezco nucho a él, sobre todo en lo introvertido. A él no le gustaba contar sus cosas, creo que a mí ne pasa algo parecido, por eso me cuesta mucho contarte todo lo mío. Contigo tengo pocas Iarreras, cada vez menos, tengo más con la gente, pero yo necesito mi parcela. Hay un límite jue no te he contado. Mi vida es mi vida y no quiero que la sepa nadie. Tengo mi vida ırdenada de una manera y si te cuento todo tendría un conflicto conmigo. Además rrofundizar mucho me cuesta, me duele, luego me obsesiono.

ucía: Claro, yo te entiendo perfectamente, cada uno queremos tener una parcelita que sea nuy nuestra. Pero también pienso que cuando tú y yo hemos tenido conversaciones más tensas tú te sentiste bien y saliste relajado. 
'icente: Si, es cierto y por eso yo quiero seguir viniendo. La verdad es que ya me va costando nenos abrirme, voy teniendo menos miedo, sé que tu sólo quieres ayudarme y veo tu ntusiasmo y tu lucha conmigo, los dos en equipo, como tu dices.

La pregunta que nos hacemos es: ¿Puede ser el episodio de la muerte del abuelo otra situación traumática, otra situación de abandono como la de la madre al no poder estar con él en el hospital de pequeño?

En este diálogo podemos ver cómo entre Vicente y su terapeuta se empieza a instaurar un apego seguro (Wallin 2012). Vicente explica que, al igual que su abuelo, él siempre ha sido reservado. Es decir hasta el momento, Vicente había sentido que compartir sus emociones con los demás era más una complicación que una ayuda, más una amenaza que una oportunidad de mejora. En el momento de esta conversación, paciente y terapeuta han acumulado un conocimiento relacional implícito (Riera 2010b), que les informa a ambos de que los temas que anteriormente habían sido tabú no sólo pueden ser hablados, sino que además generan calma y bienestar. Esta información se ha ido almacenando en los sistemas de memoria implícita o emocional después de múltiples ocasiones en las que Vicente ha tenido la experiencia repetida de que conversaciones que se hacian muy complicadas en un inicio acababan generando paz y crecimiento interior. En el psicoanálisis clásico se consideraba que la interpretación de lo que se denominaba resistencia era lo que generaba el cambio psíquico. Aquí vemos cómo es la experiencia relacional continuada entre paciente y terapeuta lo que genera un cambio en el conocimiento relacional implícito. El Grupo de Boston para el Estudio del Proceso de Cambio (Stern et al 1998, Riera 2010b) consideran que el objetivo central de la terapia psicoanalítica es que el paciente pueda modificar su memoria implícita a través de la relación terapéutica. He aquí una diferencia sustancial a la idea de hacer consciente lo inconsciente a través de la interpretación.

II

\section{REFLEXIONES SOBRE LA RELACIÓN EMOCIONAL PACIENTE - TERAPEUTA COMO INSTRUMENTO DE CAMBIO EN PSICOTERAPIA}


Al empezar a trabajar con este paciente se trataba de un chico que se había resistido durante mucho tiempo a ir a un psicólogo, de hecho fue su madre la que consiguió que Vicente consultara, aunque cargado de resistencias. Con esta premisa por delante, logramos que él llegara a participar en su curación aunque fuera al principio de una manera muy precaria. En el comienzo de la psicoterapia Vicente le dice a la terapeuta:

"Yo tengo mucho miedo a contarte mis cosas, porque sé que si comienzo a hablar luego me quedará mucha pena y mucho dolor y sé que caeré en un pozo muy profundo del que después no podré salir. Cuando empiezo a llorar me quedo tocado y bloqueado de tal forma que ya no tengo capacidad para hablar o pensar de otra cosa. Me sienta mejor no pensar. Cuando me siento mal me digo como me dice mi padre: no pasa nada, todo se arreglará".

Conviene poner el énfasis en que un elemento principal en el proceso de cambio en la psicoterapia de Vicente, no sólo ha sido ir viendo qué traumas ha tenido y sus secuelas, sino que lo más eficaz aunque quizá lo menos evidente ha sido que desde el principio y a lo largo del tratamiento, la terapeuta le ha ido mostrando que esta convicción que él tiene de que si habla de sus problemas será como meterse en un pozo y que luego no podrá salir de ahí, no es la convicción de la terapeuta. Las convicciones de los terapeutas que juegan un papel importante en las terapias son aquellas que están incrustadas totalmente en lo más profundo de su ser, que recorre sus entrañas y que su cuerpo entero se estremece cuando las sienten. Sabemos que no serviría para nada decirle a Vicente: "no te preocupes, ya verás cómo esto no es así". Lo que servirá es que Vicente note que la terapeuta no tiene el mismo miedo que él tiene. Y que sabe por experiencia que pueden recorrer esos caminos a los que él teme sin que se quede sumergido en el fondo del pozo. Y Vicente ha ido viendo cómo la terapeuta ha estado muy a su lado, en el momento de recordar y revivir sus heridas, de manera que su compañía le ha permitido poder soportar vivencias que hasta el momento había tenido que disociar. Así Vicente le dice: "yo puedo hablar contigo aquí y no tengo miedo porque tú no te asustas como yo, y entonces me siento más seguro de que quizá no me pase nada si te cuento lo que siento como más íntimo mío". Este es el resultado de la implicación emocional de la terapeuta, es decir de su predisposición a vivir con Vicente emociones tan dolorosas

Vicente tiene una convicción emocional grabada en su memoria implícita que es: no hay que revisitar los fondos que dolían tanto. Y cuando su mente se acerca a algo que le podría 
meter en el pozo, tiene una reacción automática que le hace desconectar sin previa reflexión. Sus sistemas de memoria implícita le van mandado señales de "peligro, peligro, te estás saliendo de la carretera buena, te estas dirigiendo a un pozo, al infierno, entrarás en lo que te pasó años atrás, no lo vas a aguantar". Su gran temor es tocar un tema que sospeche que le pueda poner mal, porque se queda enganchado y bloqueado. Vicente es poco ágil para pasar de un self a otro. Cuando se encuentra en un self tranquilo no quiere hacer experimentos porque según qué otro self se le active quedará prisionero hasta no se sabe cuándo. Bromberg (1996) describe el self múltiple como un conglomerado de distintos si-mismos que se activan en función del contexto específico de cada momento. Cuando predomina la disociación, el paciente tiene la convicción de que el estado emocional en el que está instalado en determinado momento va a durar para siempre, no tiene la flexibilidad para pasar de un self a otro.

Ha sido la compañía de la terapeuta, el que ella no tuviera un miedo tan desbordado como el suyo y le pudiera acompañar a profundizar reflexivamente en sus heridas, en su disociación, lo que ha permitido que el sufrimiento de Vicente se fuera amortiguando. Ha sido esa compañía sentida en la realización de un trabajo plenamente vivencial (Buechler 2015), lo que ha permitido a paciente y terapeuta, poderse sumergir en los distintos simismos de Vicente, y que él había dejado fuera de su conciencia. Un ejemplo: en una ocasión en que se encuentra mal, la terapeuta le dice: "No espero de ti que tú te tires a la piscina si no lo ves claro, no te pido heroicidades, avísame si voy demasiado rápida, pero si tú te tiras yo me tiraré contigo. Sabes que mi actitud es ir a tu lado muy respetuosamente, no ir detrás de ti empujándote o delante de ti arrastrándote, que es lo que has vivido en tu familia". Es la actitud de curiosidad, de respeto, de interés por Vicente con autenticidad, de querer estar ahí en los momentos difíciles lo que va a permitir a Vicente salir de la disociación sin que ocurra la catástrofe que él imagina.

A lo largo de las sesiones Vicente ha ido viendo el compromiso afectivo y vincular de la terapeuta con él. Por ejemplo cuando en una situación de sumo estrés en un episodio que tuvo de altercado con su hermano y donde los padres quedaron paralizados y no actuaron, Vicente está en tal mal estado que no puede quitarse de la cabeza la idea de suicidarse, y llama por teléfono a la terapeuta a las 12 de la noche y le dice que tiene un cuchillo en la mano porque no puede más. En esos momentos ella permanece conectada telefónicamente con él hasta las 3 de la mañana hasta que logra que se serene. 
Y en otro momento que la terapeuta nota que Vicente ha rebajado su interés por la terapia, su narrativa estaba siendo más aburrida, había faltado algunos días a la sesión por causas no muy justificables, había decidido de repente que deseaba tener solo una sesión en lugar de dos como había sido al principio ... Entonces la terapeuta tuvo que ir aceptando todos estos cambios, aunque no de muy buena gana, pero pensando en que la situación de Vicente era delicada se va acoplando a él, hasta que nota que ella misma se está desactivando del interés que siempre había puesto en este chico y que se está desorganizando. Al principio la terapeuta duda si hablar con él o callar y no insistir por temor a su reacción, a su fragilidad, pero después piensa que hablar sobre esto podría servir para practicar que se puede discutir y tener diferentes opiniones, pero no por eso se corta el vínculo fuerte que tienen. Y muy serenamente la terapeuta dice: Desde un tiempo para acá es como que nos hemos apagado, nuestras conversaciones son menos intensas, como que las pilas se están apagando, creo que nos hemos descentrado los dos. ¿Tú tienes esta misma sensación? Hablémoslo sin que sea el fin del mundo. Él asintió, y comentó: ahora que lo dices tienes razón, yo también lo he notado.

Otro hecho que muestra este compromiso afectivo y vincular de la terapeuta con Vicente, es que en una de las sesiones le vio tan decaído, tan caótico, tan lánguido, tan metiéndose en una rueda depresiva cada vez mayor, en definitiva tan necesitado de afecto, que la terapeuta se dirige a él y le dice:

ucia: Según te oigo ¿sabes lo que se me está ocurriendo? Abrazarte y quedarnos en silencio.

Como la terapeuta no notó oposición, se levantó y lo abrazó fuerte, con sentimiento. Él estaba rígido, como inerte, se le notaba sin expresión. Poco a poco su cuerpo reaccionó y empezó a corresponder al abrazo de una manera más emocional. Entonces la terapeuta le preguntó cómo se sentía.

'icente: Fue una idea estupenda que me abrazaras, he sentido protección, cariño, ranquilidad. Me he calmado mucho, te agradezco muy vivamente tu impulso, tu afecto, sentí jue definitivamente estabas conmigo, que ya no tenía que sentir ningún miedo, que contigo ne podía abrir confiadamente y contarte esas cosas que me había guardado para no tener jue entregarte todo y por si sentía miedo a quedarme vacío.

Después valoramos lo que ambos habíamos sentido y le comenté: 
ucía: al principio me sentí insegura por si te molestaba, pero te sentí tan inerte, como si tu verpo no tuviera vida.

'icente: estuve así porque cuando estoy tan mal me ahoga el sentimiento y me quedo sin oder mover casi los brazos ni el cuerpo, siento que mi cuerpo va por un lado y mi mente por tro. Cuando me dan ataques de ansiedad se me duermen los brazos, la gente dice que se hoga, pero a mi lo que me pasa es que se me paralizan los brazos:

_ucía: esta parálisis de tu cuerpo quizá la podríamos entender como la reaccion de defensa jue tienen todos los animales cuando se sienten bajo amenaza de muerte. Siempre que un namífero se encuentra en peligro puede reaccionar luchando, huyendo o congelándose. Son as tres estrategias biológicas de los mamíferos ante el peligro. Y es posible que esta parálisis jue tu sientes sea una activación de este tipo de reacción de congelación.

Es posible que este abrazo reactivase en Vicente las sensaciones que tenía de su abuelo y el abrazo quizá fueran una reactivación de estas experiencias que también habían quedado disociadas. Estas pocas experiencias habían sido muy dejadas de lado y abandonadas.

Obsérvese que las explicaciones de la terapeuta acerca de la parálisis en los brazos son muy distintas a la manera de entender por parte del psicoanálisis clásico las denominadas conversiones histéricas, que eran explicadas como consecuencias de un conflicto libidinal. En la actualidad, cada vez son más los enfoques terapéuticos que complementan la construcción de narrativas verbales con abordajes más directos al cuerpo del paciente, (Van der Kolk 2015) como es el caso de esta viñeta, en la que la terapeuta considera que el discurso verbal no va a tener un efecto organizador del caos emocional-corporal en el que está sumergido Vicente, y decide explorar la posibilidad de actuar directamente sobre el cuerpo a través de un abrazo. Poseer herramientas (contacto corporal sensorio-motor, bioenergética, mindfulness, relajación etc) que permitan calmar a través del cuerpo pueden ser una ayuda para que los pacientes pierdan el terror al descontrol de la angustia.

Aunque hay una influencia mutua entre sentir y pensar, nuestra perspectiva es que en la clínica suele ser más notable la influencia de la emoción sobre el pensamiento. De este interjuego entre lo que Vicente siente y lo que piensa, emerge su sentimiento de sí. Modificar este sentimiento de si es por supuesto uno de los objetivos centrales del tratamiento. A menudo Vicente contacta con sus emociones a través de la terapeuta. La terapeuta siente emociones que Vicente tiene disociadas, y Vicente puede ver sus propias emociones en el espejo de la terapeuta. "Yo siento que tu sientes lo que yo siento" describe 
bien el circuito de comunicación emocional recíproca entre paciente y terapeuta (Riera 2010a). Asimismo habrá que ir relacionando sus angustias con los hechos acaecidos en su vida. Habrá que ir encontrando que desde muy antiguo su madre, aunque estuvo siempre con él, no pudo regular sus emociones y su sufrimiento, y cómo fue un niño y un adolescente asustado, ligado a su enfermedad, y un joven desesperanzado ante el tsunami de los acontecimientos. De forma esquemática podríamos decir que Vicente sentía que su madre sentía la angustia que él mismo sentía, pero de una forma todavía más caótica y desregulada. En cambio él podía leer en su terapeuta que ésta sentía las emociones suyas, (de Vicente) de una forma más ordenada y regulada. Podríamos decir que el sistema de neuronas espejo de Vicente copiaba la manera de sentir de su terapeuta.

III

\section{EL ROL REVERSAL Y LA ACOMODACIÓN PATOLÓGICA}

Un tema principal de este trabajo ha sido entender que los padres de Vicente no fueron para él como un techo protector. Desde muy antiguo percibió que ese techo que le protegía, se agrietaba. $Y$ entonces, sin darse cuenta apenas de ello, es decir sin poderlo pensar en palabras, empezó a tener como principal objetivo ocuparse de que ese techo no le dejara a la intemperie. Y eso se convirtió en algo obsesivo donde se agruparon los sentimientos de miedo al futuro y de inseguridad. Y ahí es donde apareció y se concentró toda su angustia. Siendo un niño que está en esa tesitura, debió perder de vista sus propias motivaciones e intereses y el único estímulo que tenía es que no le cayera el techo encima. Y a eso se dedicó gran parte de su vida. Por eso cuando la terapeuta le pregunta sobre sus intereses, sobre qué le gustaría hacer con su vida, él dice: "no sé, nunca he pensado en eso". Él no se imagina una vida independiente como le correspondería a un joven de su edad: tener una novia, crear una familia, o tener una profesión que no sea la que le elija su hermano. Él no puede dejar de hacer el papel que tiene asignado en su propia familia. Vicente tiene un conocimiento relacional implícito de que no está en este mundo para progresar personalmente sino para cuidar a los demás. De ahí que el sistema de su memoria implícita le hace huir de progresar, lo rechaza, lo ve como peligroso y se angustia como cuando abandonó las oposiciones. Entre los padres y Vicente se hizo un pacto implícito, nunca expresado en palabras, que decía asi: "hijo mío, tú nunca estarás bien, porque tú eres un enfermo, pero nosotros te protegeremos, te daremos lo que tú no puedes conseguir por tu cuenta. A cambio de esto tú nunca vas a poner en discusión que tú eres así, que eres enfermizo y suerte que tus padres te cuidan. $Y$ nosotros, los padres, nos vamos a apoyar en ti sin que esto se note demasiado. $Y$ hacemos este contrato que hará que cuando tú vayas 
a aprobar unas oposiciones, te asustes porque esto es salir de tu papel de niño enfermo; que cuando tú vas a tener una novia te aterrorizas porque la novia va a ver que tú eres un chico enfermo y que cuando tu tengas una alegría te asustes porque verás que eso está fuera de contrato". Y prueba de esto es cuando en cierta ocasión dice: "Para mi padre yo estaré mal siempre, él tiene su opinión y sólo piensa: pobrecito mi hijo que con 2 años le llevamos al hospital. No sirve de nada hablarle de lo que he cambiado, él siempre pensará igual". Y Vicente queda atrapado en esto y se acomoda a la imagen que sus padres tienen de él, acepta esa imagen como un mandato, y el catastrofismo que él vive es un sometimiento a las sentencias de los padres. Esto es lo que Brandchaft denomina como acomodación patológica (Brandchaft 2007, Brandchaft et al 2010, Doctors 2011, Orange 2011). Es un patrón emocional que se activa automáticamente. Cuando en cierta ocasión la terapeuta le dice: "debes tener la sensación de que tu destino es sufrir, como si tuvieras una maldición, como si te tocara esto, como si no te pudieras escapar, él afirma: "si, efectivamente esto es lo que me pasa". Es lo mismo que cuando dice: "yo tengo una buena noticia y me pongo contento, pero inmediatamente pienso que tendré una desgracia". Tradicionalmente se ha atribuido este tipo de dinámica al sentimiento de culpa y necesidad de castigo asociado a deseos incestuosos y destructivos inconscientes. En cambio en la teoría de la acomodación patológica de Brandchaft, lo que está enfatizado es la amenaza de perder la protección de los padres si pretende escapar del papel que ellos le han atribuido. Esta dinámica está bien capturada en la metáfora del pájaro enjaulado. Entonces la terapeuta le dice a Vicente:

"A ti te pasa algo muy parecido a lo que le pasa a un pájaro que ha vivido toda su vida en una jaula. Si se le abre la puerta tiene miedo de salir y no sale. Y no es nada absurdo esto, porque es muy probable que si el pájaro saliera y se fuera al bosque no sabría vivir y duraría poco porque no sabría relacionarse fuera de la jaula. El pájaro y el dueño han firmado un contrato que dice: tu, pájaro, estarás tranquilo en la jaula, cantarás y esto a mí, tu dueño, me hará mucha compañía. A cambio yo que soy tu dueño te cuidaré, te pondré comida cada día, te limpiaré la jaula. Y por tu parte no protestarás, no me morderás el dedo cuando introduzca la comida, no intentarás escaparte".

Al final del tratamiento Vicente se da cuenta de que es él el que está protegiendo a sus padres, el que no se puede ir de casa porque ellos quedarían desprotegidos. Después de muchas horas de trabajo podemos constatar que él siempre ha estado más pendiente de ellos de lo que era consciente, de tal forma que le había resultado inadvertido, había dedicado su vida a facilitarles las cosas. Es evidente que toda esta parte la tenía muy disociada. Ahora él siente que sus padres son débiles, pero durante mucho tiempo este pensamiento era tan insoportable que iba acompañado de náuseas y vómitos. La frase que 
dice: "la que se puede liar si yo no estoy muy atento a cuidarles, si yo me voy de casa, o si se me ocurre irme de vacaciones" es significativa. "Yo tengo que animarles, siento que eso para mí es obligatorio".

Este cambio de Vicente en su forma de ver las limitaciones de sus padres empieza a raíz del problema judicial de su madre, porque con ello constata la idea que hace mucho tiempo ronda por su cabeza, y es que esta madre, que parecía segura y firme, en realidad siempre ha sido un techo frágil que en cualquier momento se le podía caer encima. Y por eso Vicente no pudo pensar si le gustaba jugar o si le gustaba ir con los amigos, sino que su mente estaba ocupada en cómo estaban sus padres, especialmente si se tambaleaba su madre.

Sentimos que es un éxito que haya ido logrando que ciertas emociones catastróficas sean menos avasalladoras, menos masivas y que se hayan podido transformar en emociones más soportables. De esta forma se ha ido creando un espacio potencial en el que han podido ir emergiendo emociones más vitales, como la ilusión y la esperanza. El resultado es que hacia el final del tratamiento Vicente puede afrontar las dificultades que van surgiendo sin sentirse un chico incapaz, puede sentirse orgulloso de su profesión, se distancia de su hermano para protegerse de sus malos tratos, y se va haciendo un mapa mental de las limitaciones de sus padres. Vicente ha cambiado el pensamiento de: "mis padres son los fuertes y yo el débil", por "yo tengo más fortaleza de lo que había pensado". Lleva un tiempo en que está claro en sus ideas y más firme en sus formas nuevas de actuar, siguiendo en general el curso de sus deseos. $Y$ siendo consciente de que a veces no puede seguirlos, pero ya se entera, ya no es que esté disociado. Tenemos en mente una frase que en cierta ocasión dijo a la terapeuta: "Cuando tú me digas que ya no tengo que venir, me darás un arma, sentiré que estoy curado y eso me hará sentirme fuerte". La terapeuta se siente en interacción emocional con él, y nota que ahora eso es real, ya no hay disociación.

Él está caminando solo. Y ahora muy recientemente Vicente ha empezado a hablar por primera vez en su vida de que le gustaría tener una pareja.

Por ello está próximo el ir distanciando sus sesiones hasta darle el alta. A la hora de organizar el final de su terapia será muy importante que Vicente esté implicado en cómo lo van a gestionar, en que él va a ser figura importante y que los dos, Vicente y la terapeuta, tomaran decisiones en equipo. Se tratará de que pueda elegir espontáneamente cómo le gustaría organizar el final del tratamiento, que pueda escucharse a si mismo y ver qué le sale, yendo despacio para que él vaya pudiendo elegir y compruebe que esto que hace ahora, antes nunca lo pudo hacer, ni siquiera se lo pudo plantear. A él, que no eligió estudios, ni qué carrera quería hacer, ni cuál sería su forma y su lugar de trabajo, le podemos 
decir: Tu eliges por primera vez algo que será notable en tu vida: empezar a caminar por tu cuenta, ahora puedes salir de esa "jaula" de la que hablamos, sin temor porque tienes armas suficientes para actuar sin miedo. Por supuesto que nunca estarás solo, que siempre la terapeuta estará a tu disposición para cualquier emergencia.

\section{REFERENCIAS}

Brandchaft B., Doctors S., Sorter D. (2010). Toward an emancipatory psychoanalysis: Brandchaft's intersubjective vision. Psychoanalytic Inquiry; v. 31

Brandchaft, B. (2007). Systems of pathological accommodation and change in analysis. Psychoanalytic Psychology 2007 Vol. 24, No. 4, 667-687

Bromberg P. M. (1996). Standing in the Spaces. The Multiplicity Of Self And The Psychoanalytic Relationship Contemp. Psychoanal., 32:509-535

Bromberg, P. M. (2009) "Reduciendo el tsunami. Regulación afectiva, disociación y la sombra de la inundación". Clínica e Investigación Relacional. 3 (1)

Bromberg P.M. (2011). The Shadow of the Tsunami: and the Growth of the Relational Mind. New York: Routledge

Buechler, S. (2015). Marcando la diferencia en la vida de los pacientes. Madrid. Ágora Relacional. Colección Pensamiento Relacional no 14 (ISBN: 9788494255922)

Doctors, S.R.. (2011). Liberando a los pacientes de los residuos de traumas relacionales: la búsqueda de Brandchaft. Clínica e Investigación Relacional, 5 (3): 517-523. [ISSN 1988-2939]

Lyons-Ruth, K., Dutra, L., Schuder, M.R. I Bianchi, I. (2006). From infant attachment disorganization to adult dissociation: relational adaptations or traumatic experiences? Psychiatric Clinics of North America, 29: 63-86.

Orange, D.M. (2011). "La Actitud De Los Héroes". Bernard Brandchaft y la hermenéutica de la confianza". Clínica e Investigación Relacional - 5 (3) 507-515. [ISSN 1988-2939]

Pally, R. (2010). The brain's shared circuits of interpersonal understanding: implications for psychoanalysis and psychodynamic psychotherapy. Am Acad Psychoanal Dyn Psychiatry 38(3):381411

Riera, R. (2010a). La conexión Emocional. Editorial Octaedro.

Riera, R. (2010b). Una breve introducción a las aportaciones del Grupo de Boston. Clínica e Investigación Relacional, 4 (2): 315-320. Sección especial: El Cambio Psíquico

Riera R (2011). Transformaciones en mi práctica psicoanalítica ( $2^{a}$ parte). El énfasis en la conexión intersubjetiva. Aperturas Psicoanalíticas № 37 . www.aperturas psicoanalíticas.org

Stern D.B. (2003). Unformulated experience: from dissociation to imagination in psychoanalysis. Hillsdale, NJ; The Analytic Press expresa. Este material es para uso científico y profesional exclusivamente y puede contener información clínica sensible. Los editores no se responsabilizan de los contenidos de los autores. Dirigir las consultas sobre derechos y autorizaciones a ceir@psicoterapiarelacional.es 
Stern, D. N., Sander, L. W., Nahum, J. P., Harrison, A. M., Lyons-Ruth, K., Morgan, A. C., Bruschweilerstern, N. and Tronick, E. Z. (1998). Non-Interpretive Mechanisms in Psychoanalytic Therapy: The 'Something More' Than Interpretation. Int. J. Psycho-Anal., 79:903-921

Stolorow, R., Atwood, G., \& Orange, D. (2002). Worlds of experience: interweaving philosophical and clinical dimensions in psychoanalysis. New York: Basic Books.

Van Der Kolk (2015). El cuerpo lleva la cuenta. Editorial Eleftheria 2015. (ISBN 9788494408403)

Wallin, D.J. (2012). El apego en psicoterapia. Colección Biblioteca de Psicología. Desclee de Brouwer, (ISBN 9788433025494)

Original recibido con fecha: $\quad$ 18-9-2016 Revisado: 15-10-2016 Aceptado: 31-10-2016 